\title{
Mapping the lived experiences of Bangkok's soi
}

\author{
Davisi Boontharm \\ Sophia University, Tokyo, Japan \\ Centre for Global Discovery \\ davisi@sophia.ac.jp
}

\begin{abstract}
One of the most distinctive urban characteristics of Bangkok is its sois. Soi is an alley that branches out from the main thoroughfares. This terminology applies to both the artery system of streets and canals. Soi is considered as a sub-street or a tertiary type in the hierarchy of the streets of Bangkok, the spatial layout of which follows old agricultural patterns of the water based settlement. They produce the labyrinth-like spatial and social configurations initiated by various agreements and practices between the landowners and residents. The public investment in road infrastructure couldn't cope with the speed of urbanisation in Bangkok. Apart from the main roads constructed by the public authorities, the soi where the majority of population in Bangkok lives is created by private initiative. For this paper, I only present part of the bigger project, which is still on going. In this very initial state of my investigation, I focus only on one family; mine.
\end{abstract}

Keywords: public space; Bangkok; superblock; soi; mapping.

To cite this article:

Boontharm, D. (2016). Mapping the lived experiences of Bangkok's soi, The Journal of Public Space, I(I), 43-52, DOI: 10.5204/jps.vlil.9

This article has been peer-reviewed and accepted for publication in The Journal of Public Space. Please see the Editorial Policies under the 'About' section of the journal website for further information.

\section{(c) (1) \$}

This work is licensed under a Creative Commons Attribution - Non Commercial 4.0 International License. https://creativecommons.org/licenses/by-nc/4.0/ 
One of the most distinctive urban characteristics of Bangkok is its sois. Soi is an alley that branches out from the main thoroughfares. This terminology applies to both the artery system of streets and canals. Soi is considered as a sub-street or a tertiary type in the hierarchy of the streets of Bangkok, the spatial layout of which follows old agricultural patterns of the water based settlement. Soi branches away from the main street bringing access into the innermost parts of the superblocks (Boontharm, 2013). They produce the labyrinth-like spatial and social configurations initiated by various agreements and practices between the landowners and residents.

Bangkok used to be known as the "Venice of the East," with life orientated towards its complex water system of Chaophraya river and its canals and irrigation structures.

Throughout 234 years of development, the city has undergone a tremendous change, evolving from its traditional, aquatic roots (Jumsai, 1997) and distinctly tropical green city character into a megacity of artificial topographies of concrete.

The end of the nineteenth century was the period when Bangkok still maintained the feel of an amphibious city. Starting from the end of the nineteenth century, it evolved into a sprawling system of land-based settlements, while the mid-twentieth century until today marked of the most drastic urban transformations. For the last five decades, despite the great effort of producing urban planning documents by the authorities to shape Bangkok, none of those plans were successfully implemented. Reasons are the lack of statutory force and law enforcement, the inability of government agencies to coordinate and cooperate, and the supremacy of property interests in the fast growing city ( $\mathrm{Nim}, \mathrm{1963}$; Askew, 2002).

The public investment in road infrastructure couldn't cope with the speed of urbanisation in Bangkok. Apart from the main roads constructed by the public authorities, the soi where the majority of population in Bangkok lives is created by private initiative. In the peri-urban of Bangkok, where more than tens of square kilometres are occupied by hundreds of thousands of people, the process of urbanisation happened exclusively by the juxtaposition of private allotment projects. Very few of the secondary streets link to the main public roads, to relieve the surcharge of traffics on those main public corridors. (Charmes, 2002). Bangkok followed an erratic expansion of the soi system and dependence on automobiles, which caused seemingly endless ribbon developments, often leaving huge enclaves of inaccessible land locked within the heart of the unplanned superblocks. Seen from this perspective, soi is the result of the opportunistic private land market made by and for affordable middle class society. At the same time soi is socially produced urban fabric, issued from the negotiation of right to access which leads to right to construct and accumulative lived experiences. The production of soi is a progressive phenomenon, and took a long time to process.

Superblock and soi are typical Bangkok's suburban landscapes. There are common characteristics among the soi in Bangkok, such as the width of approximately 4-6 meters, enough for two cars to pass in opposite directions. This narrowness conditions the speed of the traffic to slow movement. However, each soi has its own pattern, its own turns and its own dead-ends. Each soi has its particular history, its way of life and its local social construct. The main roads and the soi are the juxtaposition of two completely different worlds. Pichard-Bertaux expressed these phenomena as "Soi is generally described as narrow, winding and dark while the main road is the symbol of progress, opulence and bright. However these two worlds are far from opposing each other, they complement 
each other and can't be dissociated (Pichard-Bertaux, 20I I). The spot where the two worlds connect is pak soi (mouth of the soi). It is a strategic place which acts as the gate to the hidden community inside. It is also the node of activities, one can find the concentration of shops catered to everyday activities, such as newsstands, drugstores, convenience stores, food and drink stands, and public transport nodes. This location also attracts several informal push-carts offering diverse food and goods.

Within the context of relentless, uncontrolled, rapid and heavy transformation of Bangkok, a number of local readjustments were taking place. Within such contexts, one can identify a number of ideas and examples of situation-, time- and place-specific inventiveness. For example, the self-organized transportation system - such as motorbiketaxi services which facilitate residents' travel within the soi, or the minivan bus system, which helps people move from the centre to their suburb without many stops, or diverse types of mobile vendors who serve the residents who live deep in the soi (Polakit and Boontharm, 2008).

The vast superblock with its complex labyrinth-like pattern of soi creates a tapestry of neighbourhoods, with a different sense of belonging by their residents. Soi indeed can be like a business street or thoroughfare or even an intimate lane of a quiet residential compound depending on its location, configuration and practices. Soi are complex, offering many things to diverse groups of people. For residents, they are the stages at which fully lived local lives and urban practices unfold, they are produced in an interplay of those lives and their other characters. Soi, as any other urban phenomenon in Bangkok, are not "purely" lanes, they are conflictual frameworks of an unfolding complexity. For this reason, the investigation of soi urbanism cannot be achieved by the knowledge of a single discipline alone (Arkaraprasertkul, 2010). The purpose of this paper is to argue for the trans-disciplinary methods of investigating the realm of a neighbourhood in the specific context of Bangkok's superblock and its soi from the perspective of the residents' lived experience. For those with lived experiences in this environment, soi are never the background notion of concrete everyday lives and memories of concrete people. By referring to Lefevbre's trialectics, exploring those spaces as conceived, perceived and lived, I discuss the complexity of socio-spatial production of the concrete neighbourhood. As I want to emphasise the importance of concrete, real lives of concrete, real people in concrete, real situations, my particular emphasis will be on vécu, the lived experiences which I can unpack both as an academic and as a long-time resident - those of my own family members, including myself, and acquaintances in the soi.

For this paper, I only present part of the bigger project, which is still on going. In this very initial state of my investigation, I focus only on one family; mine. Lefebvre (1974) suggests that the body is one useful way to locate and understand how space is socially produced. In this particular case the "body" is me and each of my family members'. I am aware of the limitations that I and my family can only establish part of the whole representation of soi Aladin. My complete research is aimed at capturing multiple stories from broader groups with a deep level of local involvement and knowledge.

By addressing the vécu, the approach to an individual's living experience is necessary, and the subjectivity in the method of enquiry is unavoidable. Human experience is important in urban research; it is always situated in a social, cultural, and spatial context. Individuals directly and indirectly are subjects of conditions of their social milieu. To record and communicate the deep meaning and the sense of neighbourhood, I combine the method of narrative and mapping as an attempt to present the non-measurable and qualitative 
aspects of the place. The story of my neighbourhood cannot be told without the presence of the soi. Soi is not only the spatial structure of the neighbourhood, it is also the physical and mental space where body movements and social interactions occur. I hope that through layering different individual stories of diverse experiences of the past and present we can reassemble the content (physical, spatial and social) and their relationships and achieve some kind of reading of this concrete neighbourhood.

At this initial stage of research, I only attempt to experiment with this method through my own family. The results are not intended to offer a complete understanding of the neighbourhood social construct, but my aim is to start with "one of" the complex whole and the most meaningful. In this paper, I value the subjective views of each family member's experience. Those subjective views could constitute important parts of the significantly understandable picture of soi Aladin neighbourhood.

Radović $(2014,2016)$ argues for the legitimacy of subjectivities in the investigation of the urban:

[...] in urban research we need to multiply subjectivities, to both ... flatten subjectivities - to make a statistical sample, or far more interesting... and ... layer subjectivities - to keep each and every of them simultaneously individual and contextual

I challenge the layer of subjectivities and avoid flattening them. For this paper, I have selected three narrative maps of my siblings and mine who were born and grew up in this neighbourhood. The maps describe the living experiences in the neighbourhood of soi Aladin. I let them tell their personal stories and express their feelings, thought and emotions about this neighbourhood, including how they describe the boundary or the realm of this neighbourhood. The record of their and my experience is done through writing. I advocate the "sketch and script" methods (Boontharm, 20I2; 20I5), in this particular case "mapping and narrative, graphical/artistic representations and texts. This spatial narrative would let the reader freely perceive. They are a patch-work of facts and feelings.

I use mapping techniques to translate those narratives to spatial form. Through this process, an active engagement between me and the texts have occurred. There is a challenge in mapping subjectivities. Mapping the narrative is to give another dimension of understanding the built environment; it could link the stories to space or just an illustration, a chart, a picture or a work of art on its own. I deliberately do not seek the dull, systematic and informative mapping, but push it towards thought, emotions and aesthetic. Do I map the reality or my imaginary? Or map the unmappable? (Radovic, 2016)

[...] I can only be sure (and even that only to a certain degree) that that I can know what matters - to me...(subjectivity... subjectivities) ... mapping is process of spatial representation of thoughts, emotions, feelings... spatial expression of somebody's ... some - body's (individual or collective body) experience, thought, hunch...[...]

[...] Mapping subjectivities opens fascinating fields for urban research... the subjectivity of the researcher... the subjective of the researched... the subjectivities of the researched $[\ldots]$

(Radović, 2016)

The aim of employing the sketch and script methods isn't only about subjectively and 
forcefully glorifying and bringing excitement to my unexciting and mundane soi. This method is an open field which invites readers to subjectively read and contemplate these representations, as one of the dimensions, the long neglected dimension in urban research (Radović 20I4, 2016).

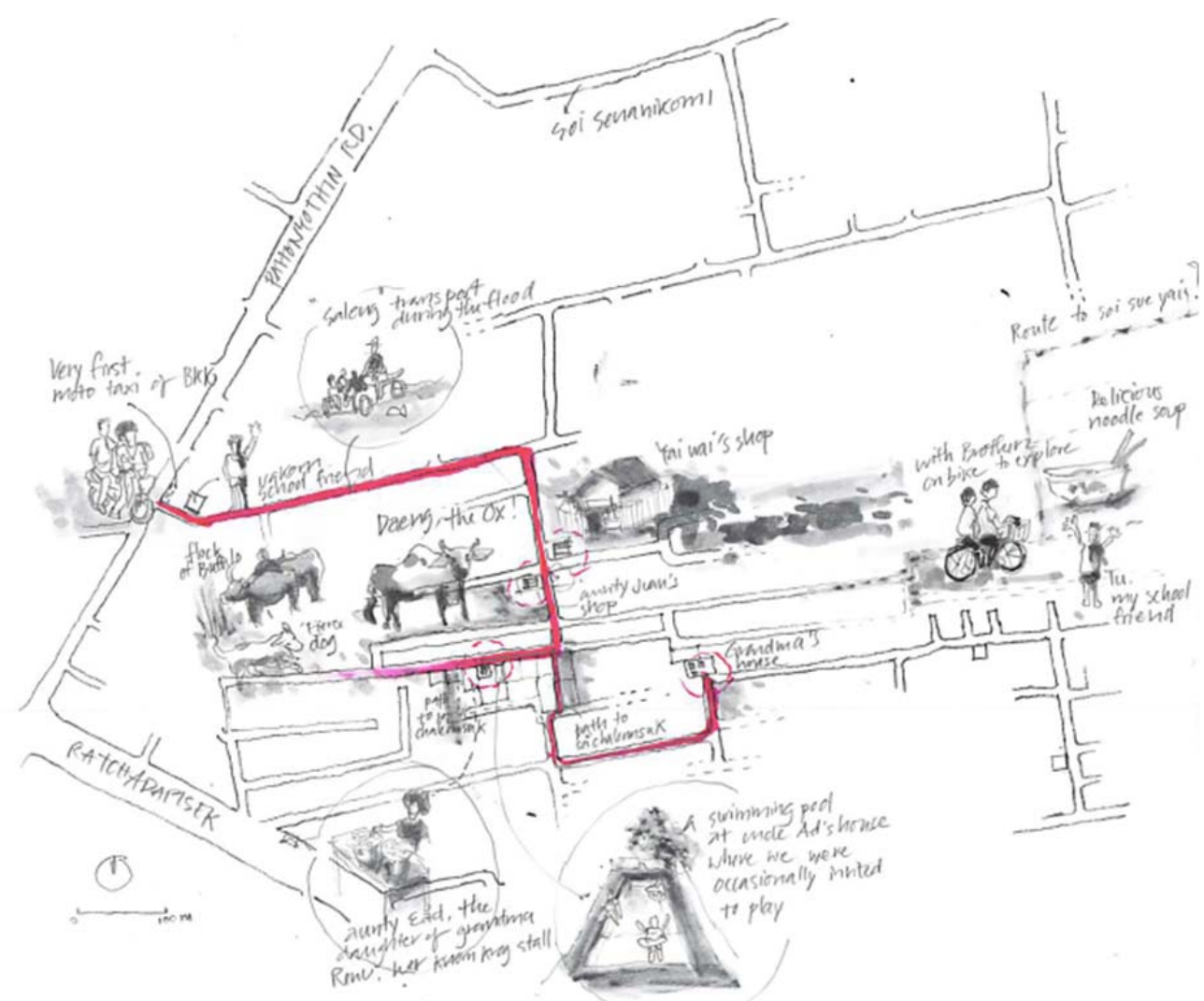

Fig. I. SKETCH - mapping narrative of my eldest brother

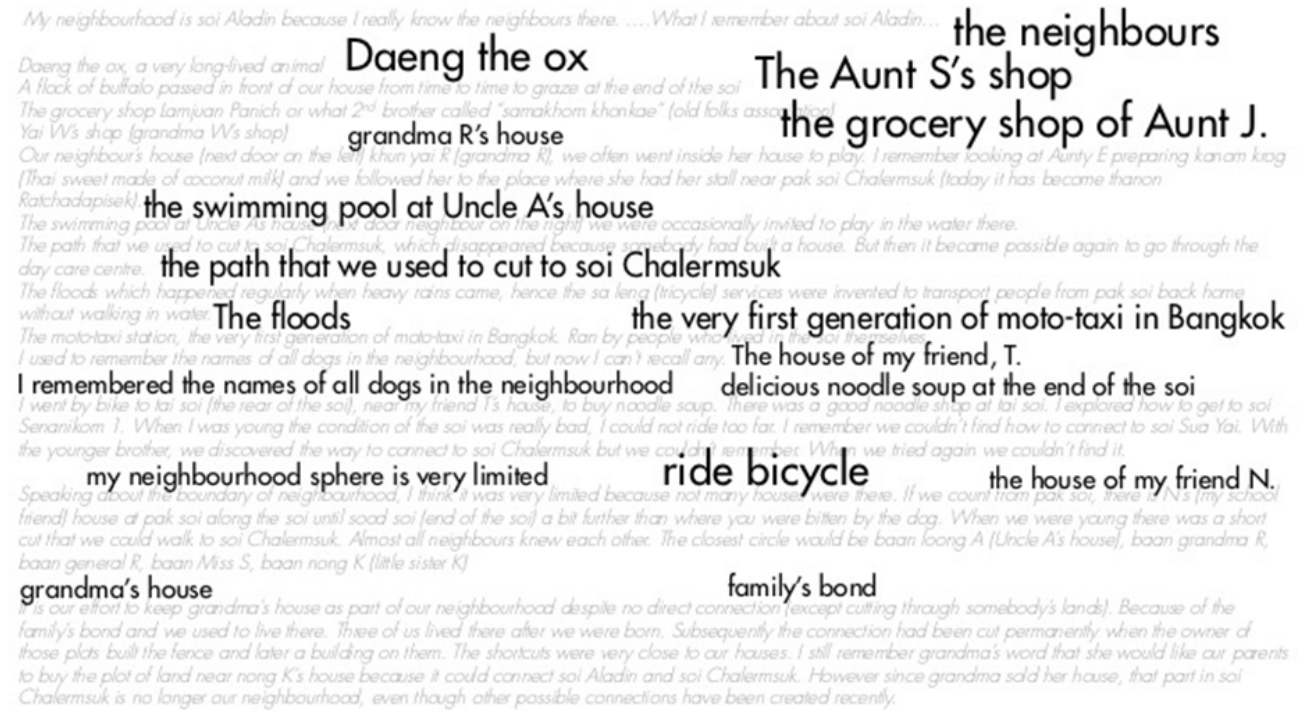

Fig. 2. SCRIPT - the narrative of my eldest brother with the highlights of important keywords (the bigger size of words represent the aspects that are common and found in other narratives). 


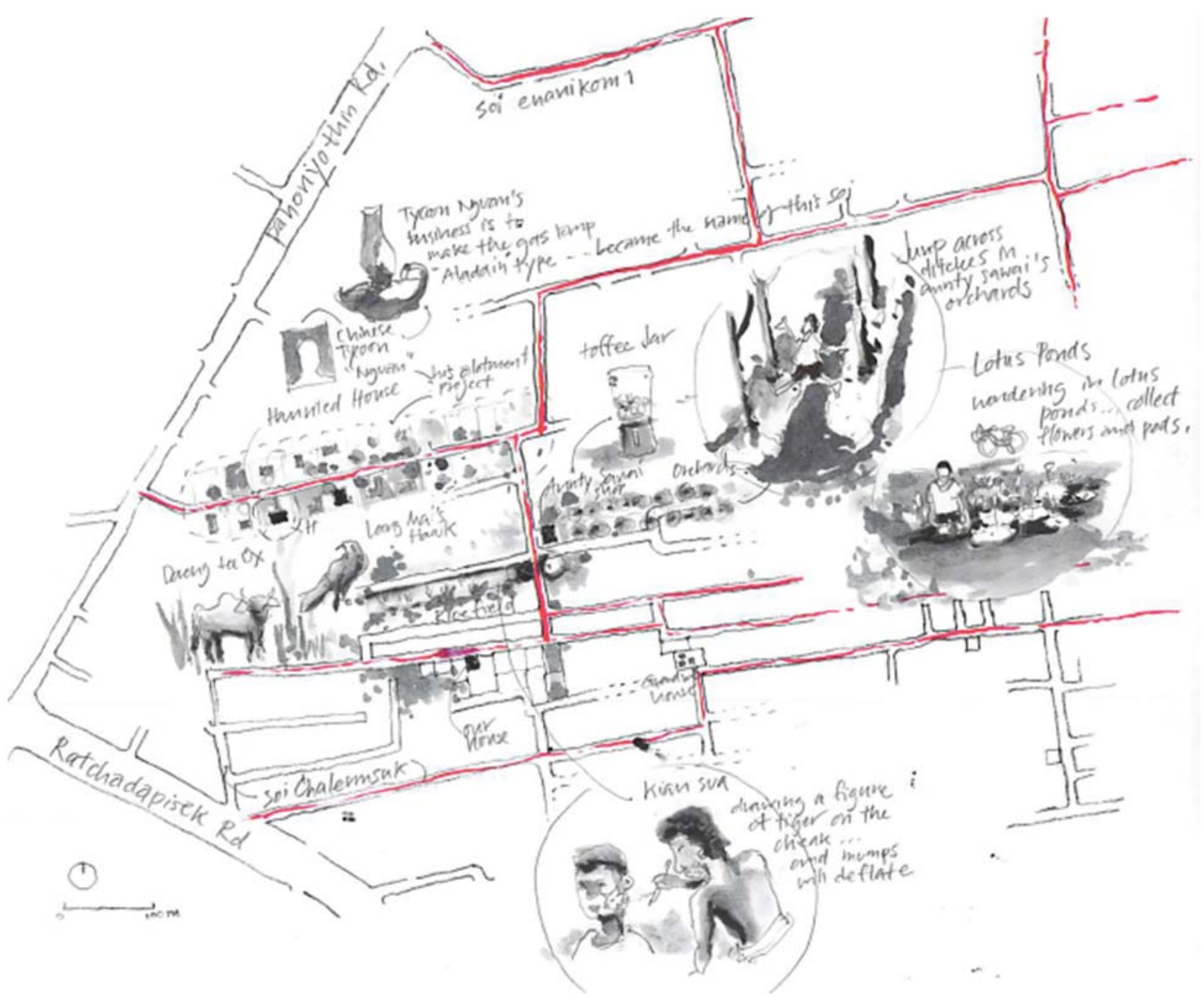

Fig. 3. SKETCH - mapping narrative of my elder brother

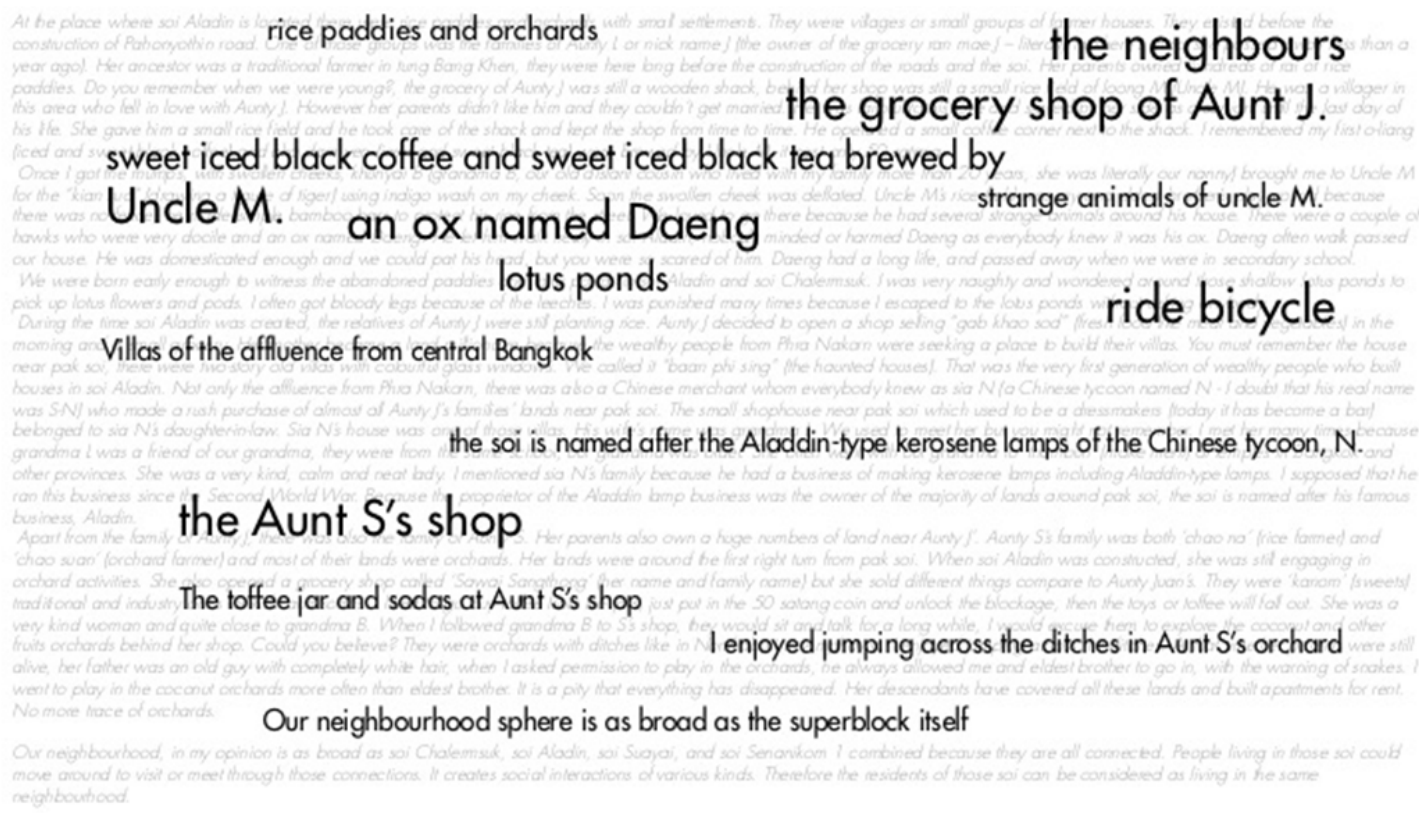

Fig 4. SCRIPT - the narrative of my elder brother with the highlights of important keywords (the bigger size of words represent the aspects that are common and found in other narratives). 


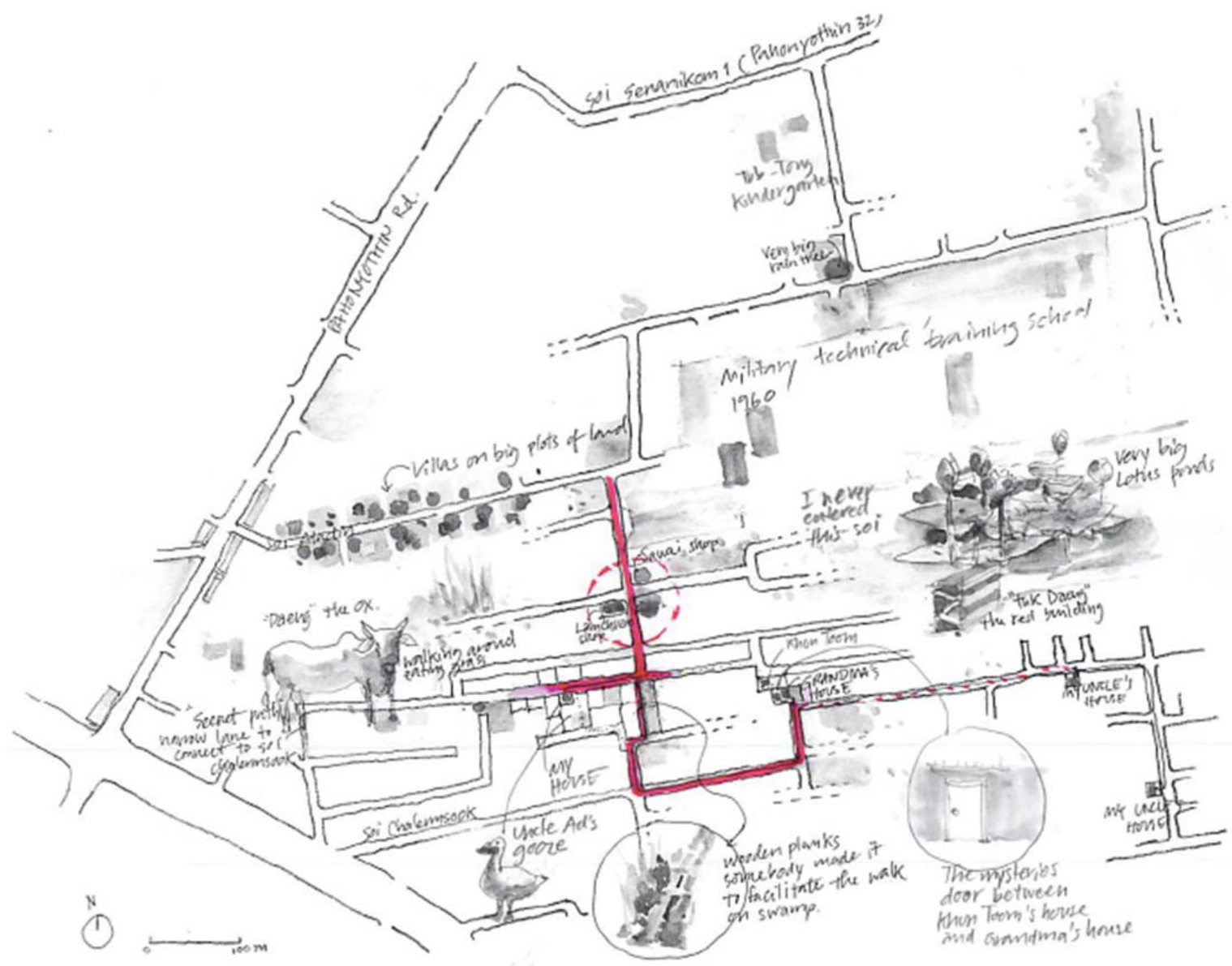

Fig. 5. SKETCH - my mapping narrative

\section{the walk to my grandmother's house}

The short cut through the empty plots of land
the secret path
a fierce goose
the mysterious door
Uncle M

the swimming pool at Uncle A's house

The floods

lotus ponds
Daeng the ox

\section{Aunt S's shop the grocery shop of Aunt J.}

the neighbours

\section{learning to ride bicycle}

the noise of cats fight

the boundary of my neighbourhood changed through time

Fig. 6. SCRIPT - my narrative with the highlights of important keywords (the bigger size of words represent the aspects that are common and found in other narratives). 


\section{Discussion}

Maps assist me in reading soi as the spine of our neighbourhood. The group of farmers' houses (Aunt J's and Aunt S's families) is the historical core of this neighbourhood. The narratives suggest that both of them are entitled to be credited as community founders. The North-South axis of soi Aladin, is the vertebral colon of the neighbourhood. This is the traditional and symbolic centre of space prior to the arrival of the soi itself. The semirural atmosphere around the junction J and $\mathrm{S}$ shops could resist the fierce urban development for several decades, but nothing lasts forever in Bangkok.

\section{I) Childhood - Neighbourhood}

Examining the personal attachment to the neighbourhood of soi Aladin, my brothers and I share strong attachment to the neighbourhood of our childhood. Many scholars who study the importance of childhood neighbourhood confirm that the street and path, and in my case the soi can "allow children to develop social competencies and to perform or enact their growing maturity through movements in and away from the home and their neighbourhood" (Christensen and O' Brien 2003). The bicycle routes that my brothers took allowed them to "explore their local place, and by accumulating such knowledge they gained confidence and could become the users of the city" (ibid).

Soi Aladin offered us an array of places to explore. We could acknowledge the rice paddies, the lotus ponds, and the orchards as sensed, perceived and experienced reality; they are stored within our bodies as tactile knowledge and a "community of senses" (Rasmussen and Smidt 2003). We were making meaning of our environment through our bodies and their movements. This neighbourhood provided "the emplaced knowledge in localities through a multitude of places, items and people" (ibid). All the aunties and uncles of the neighbourhood were the persons with whom we established social connections outside the family and school units. Animals, trees, ponds, and ditches were items that our bodies interacted with. Rasmussen and Smidt conclude the importance of childhood and neighbourhood nicely as:

The neighbourhood is perceived by the children through a number of concrete parts, where social, cultural and physical elements are inseparable and interwoven. The children are present in the neighbourhood, and they have the neighbourhood 'under their skin'.

(Rasmussen and Smidt, 2003).

\section{2) Neighbours}

Neighbourhood is all about neighbours and those face-to-face relationships. In those narratives several names were repeated. The closest ones are next door, close enough that we could penetrate into their private realm. The key people in the neighbourhood are important, in our narratives, Aunty J, Aunty S, and Uncle $M$ were the main characters and my brother and I interacted with them closely during our childhood.

As kids, my brothers and me addressed them in the Thai way using the terms we call our relatives (brother, sister, aunt, uncle, grandma etc.) Knowing neighbours and having an established relationship is the first step to feeling and creating the neighbourhood. However, not all neighbours had a good relationship. 


\section{3) Permeability}

Social space doesn't always need to be in the public space, as for soi Aladin, there is no other public space except the alley itself. The alley allows connections to happen. But with good social contact, the barrier between public alley and private realm can be permeated; like my brothers who could get into the rice field and orchards of the neighbours, or mysterious doors which allowed neighbours to cut across each other's property to connect across the soi. Was it possible only when we "knew" and "trusted" our neighbours? Was it possible only for the past generation; during the time when everybody knew everybody and when soi Aladin was still more of a village than a city? The shop of Aunty J was a shack without fence and completely open. There were big trees on both sides of the alley. There were benches for anybody to sit and buy drinks. This is the way of traditional life in a village. Her family houses were the centre of this settlement. This openness also invited customers and passer-by to come in and go out easily, or sit for a while.

The permeability is also applied to the path or short-cut on un-built land to cut across the two sois. People in the soi share that tactile practice. Especially when we live on the edge of a superblock, only locals know how to get out to the main street using these secret paths.

\section{4) Realm of Neighbourhood}

The narratives and mappings above demonstrate the impossibility in finding the cohesion of the exact neighbourhood sphere among the family members. Even people from the same family with the same background perceive the realm of their own neighbourhood completely different. This could support the frustration that scholars encounter while they agree upon a single definition of this construct. The sense of neighbourhood is definitely non-measurable; this slippery term is as complex as the city itself. In spatial terms, my siblings and I could not agree on one exact boundary of our neighbourhood but through their descriptions, our realm of neighbourhood is linear. It was constructed linearly and it stays linearly in our mind.

Unlike the moobanchadsan (housing estate or gated community) where the association of residents and common facilities are formed and active (Askew, 2002), soi Aladin doesn't have any of those. There were no official organisation and no common spaces, we only have the ordinary and mundane soi. The social structure of soi Aladin is invisible, but if I may point out the node of intensity of our social interaction, it would be at the corner shop of Aunty J. The history and the formation of this soi evolved around her and her family's lands. In this context, when an epicentre of a neighbourhood is formed around a unique person, that neighbourhood is socially quite vulnerable. Since Aunty J closed her shop and later passed away, the heart of this fragile community has vanished.

My eldest brother and I agreed on the deflation of our personal realm of neighbourhood. That tactical connection through somebody's land is also a weak connection. It confirms that in the case of soi Aladin, as many other soi in Bangkok, the private interest usually comes before the collective one. The path that has been collectively built and used for almost twenty years can be easily blocked and disconnected. Because of this simple gesture, the path that could ease the bond between families has been cut. 


\section{References}

Arkaraprasertkul, N. (2010), "Dynamic Soi: Neighbourhood and urban life" in Rian Thai: International Journal of Thai Studies, Vol. 3/2010, Bangkok: Institute of Thai Studies, Chulalongkorn University.

Askew, M. (2002), Bangkok: Place, Practice and Representation, London: Routledge.

Boontharm, D. (20I2), "Sketch and Script: made in/of Split", in Radovic D., Boontharm D., Kuma K., Grgic A., Split Case : Density Intensity, Resilience, Tokyo: Flick Studio and IKI, PP. 64-7I.

Boontharm, D. (20I3), "Bangkok Spontaneous Urbanism : Threat or Treat?" In the journal CONTESTI: Cities, Territories and Projects, Volume I/2012, Department of Urban and Regional Planning, University of Florence, pp.75-82.

Charmes, E. (2002), «La trame viaire périurbaine de Bangkok face aux théories dominantes de l'action collective», Autrepart, 21 : 17-26. DOI : 10.3917/autr.021.0017.

Christensen, P., O'Brien M., ed. (2003), "Children in the City, Introducing new perspectives" in Children in the city, Home neighbourhood and community, London: Routledge.

Jumsai, S. (1997), Naga: Cultural Origins in Siam and the West Pacific, Bangkok: Chalermnit Press and DD Books.

Lefebvre, H. (1974), La Production de l'espace, Paris: Anthropos.

Nims, C. (1963) City Planning in Thailand, Bangkok: City Planning Office, Ministry of the Interior.

Pichard-Bertaux, L., (20II) « Le tout et son contraire : une lecture de Bangkok», Moussons [Online], Online since 19 November 2012, accessed on 20 June 2016. URL: http://moussons.revues.org/757.

Polakit K., Boontharm D. (2008), "Mobile vendors: persistence of local culture in the changing global economy of Bangkok" in Local Sustainable Development in Global World, HEBERIE L., OPP S., (eds.), Pp. 175-202, Ashgate.

Radović, D. (20I4), Subjectivities in Investigations of the Urban: the Scream, the Mirror, the Shadow, Tokyo: flick Studio.

Radović, D. (2016), "Measuring the non-measurable: On mapping subjectivities in urban research", in City, Culture and Society, 7(I), Pp. 17-24, Elsevier.

Rasmussen, K., Smidt, S. (2003), "Children in the neighbourhood: the neighbourhood in the children" in Christensen P., and O'Brien M., (ed.), Children in the city, Home neighbourhood and community, London: Routledge.

Sintusingha S. (2006), Sustainability and urban sprawl: Alternative scenarios for a Bangkok superblock, Urban Design International. 